\title{
Model Calibration Efforts for the International Space Station's Solar Array Mast
}

\author{
Kenny B. Elliott ${ }^{1}$, Lucas G. Horta ${ }^{2}$, and Justin D. Templeton ${ }^{3}$ \\ NASA Langley Research Center, Hampton, Virginia 23681 \\ Norman F. Knight, Jr. ${ }^{4}$ \\ General Dynamics Information Technology, Herndon, Virginia
}

\begin{abstract}
The International Space Station (ISS) relies on sixteen solar-voltaic blankets to provide electrical power to the station. Each pair of blankets is supported by a deployable boom called the Folding Articulated Square Truss Mast (FAST Mast). At certain ISS attitudes, the solar arrays can be positioned in such a way that shadowing of either one or three longerons causes an unexpected asymmetric thermal loading that if unchecked can exceed the operational stability limits of the mast. Work in this paper documents part of an independent NASA Engineering and Safety Center effort to assess the existing operational limits. Because of the complexity of the system, the problem is being worked using a building-block progression from components (longerons), to units (single or multiple bays), to assembly (full mast). The paper presents results from efforts to calibrate the longeron components. The work includes experimental testing of two types of longerons (straight and tapered), development of Finite Element (FE) models, development of parameter uncertainty models, and the establishment of a calibration and validation process to demonstrate adequacy of the models. Models in the context of this paper refer to both FE model and probabilistic parameter models. Results from model calibration of the straight longerons show that the model is capable of predicting the mean load, axial strain, and bending strain. For validation, parameter values obtained from calibration of straight longerons are used to validate experimental results for the tapered longerons.
\end{abstract}

\section{Introduction}

Tn the current configuration of the International Space IStation (ISS), shown in Fig. 1, there are sixteen solarvoltaic blankets that provide electrical power to the station. Each pair of blankets is supported by a deployable boom called a Folding Articulated Square Truss mast (FAST Mast), a deployment canister, and end cap assembly ${ }^{1-5}$. The solar array wing is designed to be deployed and stowed as required. When deployed, the mast is 1296 inches in length and has a 30.4 inch square cross-section. At certain ISS attitudes, the solar arrays can be positioned such that a condition exists where one solar array may shadow either one or three longerons in the mast of itself or a neighboring solar array. This array shadowing event causes an asymmetric thermal loading of the mast resulting in an imbalance in the internal

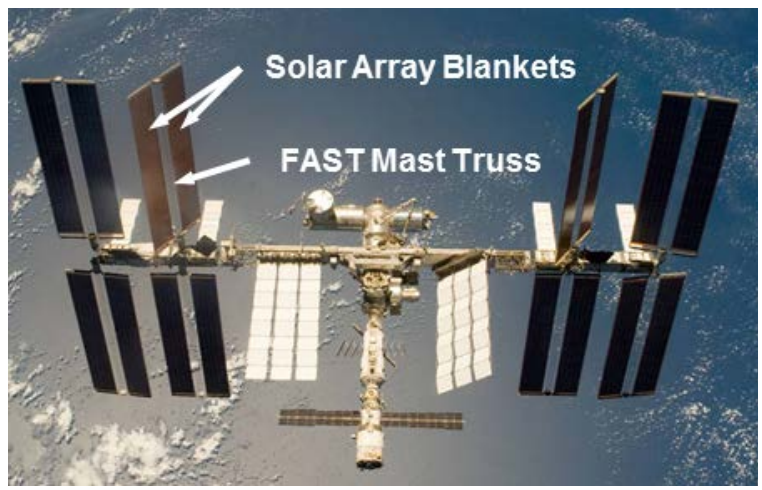

Figure 1. International Space Station. loads. One diagonally opposite pair of longerons will go into tension while the other pair will be compressed. Under extreme conditions the compressive load may be sufficient to exceed the operational stability limits of the mast. Currently, the ISS Program is managing the thermal buckling threat through careful operations planning.

\footnotetext{
${ }^{1}$ Aerospace Engineer, Systems Integration \& Test Branch. Member AIAA.

${ }^{2}$ Aerospace Engineer, Structural Dynamics Branch. Associate Fellow AIAA.

${ }^{3}$ Aerospace Engineer, Systems Integration \& Test Branch. Member AIAA.

${ }^{4}$ Principal Subject Matter Expert, Structural Mechanics. Fellow AIAA, Fellow ASME.
} 
This limits the station's operations and causes potential conflicts between optimum array configuration, nominal events, off-nominal events, and safe operations.

The ISS Program has requested the NASA Engineering and Safety Center (NESC) to assess the mast strength and stability under asymmetric thermal loading to insure proper engineering rationale is being used to set safe operational limits. Analysis of the mast's response is a multidisciplinary effort involving thermal and structural disciplines, and the focus of the NESC assessment is the development of thermal and mechanical analytical models that predict the behavior of the mast during a thermal shadowing event. These 'predictive' models are then used to assess the conservatism in the engineering models currently used to assess the response of the mast to a thermal shadowing event. Originally, a traditional approach to model validation was adopted; i.e. the models were calibrated to match the results of a combined thermal/mechanical test on a sub-assembly of four bays and the final models declared 'validated" ${ }^{6}$. However, several concerns surfaced about the use of these models. The first question concerned the uncertainty of the 'validated' model's predictions. There was insufficient information to address this concern. This became particularly important since these new models are to be 'predictive' and normal conservative assumptions were not adopted. The second question concerned whether the models are valid only for the calibrated test (point calibration). Predicting on-orbit behavior is an extrapolation. Several reviewers were concerned that without the protection of conservative assumptions, the extrapolation may lead to the wrong conclusions.

To address these issues, a strategy incorporating the principles of the ASME Standard V\&V 10-2006 ${ }^{7}$ was developed in which a building-block approach to the model development was adopted. The modeling progresses from simple components up through the full assembly. At each modeling step, the models are verified, calibrated, and validated, and estimates of the model uncertainty are included at each step. The goal is to produce a model that predicts the response to a thermal shadowing event including an estimate of the uncertainty in that prediction.

To analyze the solar array mast, it is best to work using a building-block progression from components, to units, to assembly. Understanding the response of the mast (assembly) is dependent on understanding the response of a single bay (unit), that is in-turn dependent on understanding the response of the components of the bay. In this assessment, a four-bay replica mast was developed to perform thermal/mechanical tests that were used to calibrate the original models ${ }^{6,8,9}$. The existence of this hardware combined with spare parts allows for the development of calibration and validations tests at three building-block levels: component, unit, and subassembly. Testing at the assembly level (on-orbit tests) to generate calibration or validation data is not within the scope of this assessment. Therefore, validation of an on-orbit mast model is not possible. However, the thermal/mechanical tests performed on the four-bay replica can be leveraged to provide validation data of an extrapolation from a single-bay model to a four-bay model. The four-bay configuration represents a subassembly in the building-block. The unit level building-block is the single-bay configuration, shown in Fig. 2. There are two types of single bays. One type of bay, located in the first eleven of the last twelve out-board bays of the mast, is composed of 'straight' longerons with a 0.5 inch square cross-section over most of their length. A second type of bay, located in the first twenty and last bay, uses 'tapered' longerons with a 0.59 inch cross-section over most of their length. At the component level, the basic load carrying building block is the longeron. As shown in Fig. 2, there are eight longerons in a single bay; four upper longerons, and four lower longerons. There are only minor differences in non-load carrying parts of the geometries between the upper and lower longerons. The two different types of longerons allow for calibration and validation data to be gathered at the component and unit level. At the component level, data from tests of straight longerons are used to calibrate a straight-longeron model. The modeling process and properties from the straight longeron are used to construct a model of the tapered longeron. Data acquired from testing of the tapered longeron is then used for validation. Although not covered in this paper, the same process can be used at the single-bay unit level. Data from tests of the straight-longeron single bay are used to calibrate a model of the straight-longeron single bay. The model is then converted to a taperedlongeron configuration and data from the tapered-longeron single-bay tests are used to validate the model.

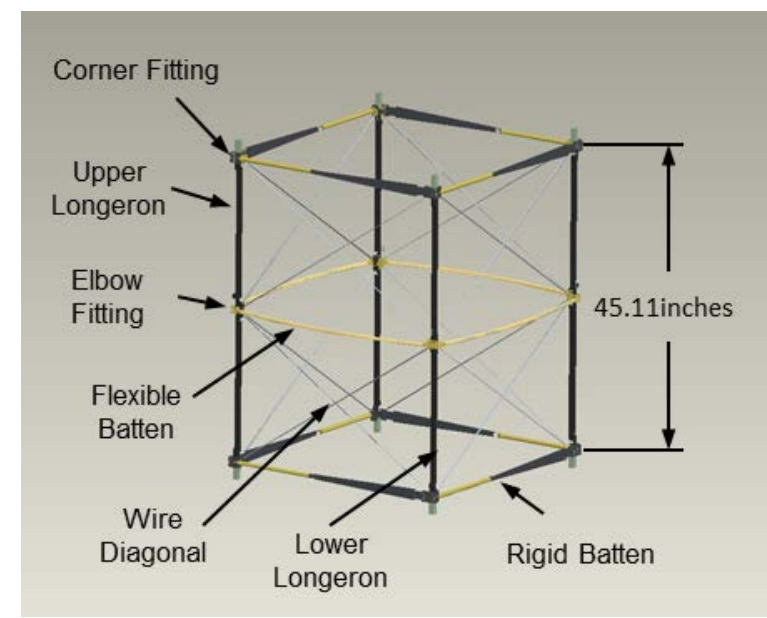

Figure 2. FAST Mast single bay configuration.

The purpose of this paper is to present the calibration and validation of the longeron components used in the mast construction. The longeron modeling is presented first followed by the testing performed to generate 
calibration and validation data. Next, the strategy used to calibrate the straight-longeron model is presented. This includes a discussion of the calibration metrics and model parameter selection. Then the calibration results are presented and discussed. This discussion is followed by a presentation of the tapered-longeron validation results.

\section{Longeron Modeling and Testing}

\section{Longeron Modeling}

The structural modeling of the longeron, as part of a single bay, is presented in detailed in Ref. 10. The model is developed to predict, with the simplest model possible, the elastic buckling response of an axially loaded straight longeron. Fig. 3 shows a typical longeron. The longeron is a square cross-section column with pinned-pinned boundaries. The over-all length is 20.25 inches with a pin center-to-center length of 19.75 inches. For connections with the rest of the structure, one end of the longeron has a clevis (elbow end), and the other end has a tang (corner end).

Although the basic
configuration is simple, there
are a few features that make
the longeron difficult to model.
First, the geometry of the
clevis and tang yields a line of
action along the column that is
not through the neutral axis
resulting in a certain amount of
eccentricity. This eccentricity
exists in the plane containing
the pin axis of rotation and the
plane orthogonal to the pin

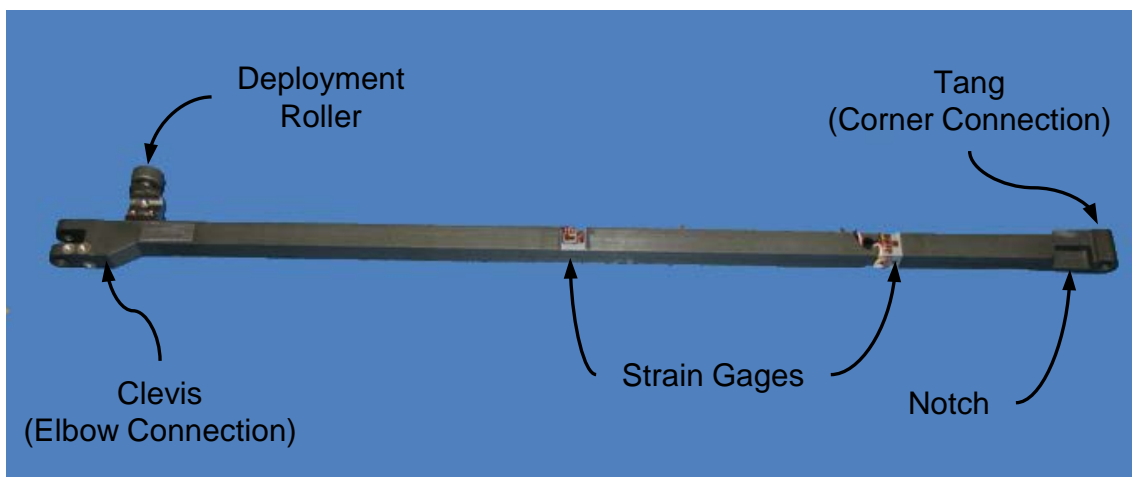

Figure 3. Typical longeron.

axis. Second, the pin joints are a tolerance fit. Therefore, there is a small amount of free-play associated with the joint. Third, as the pins contact the longeron tang or clevis, under tensile or compressive loading, a non-linear stiffness develops due to the changing contact area. Fourth, the pins are dry fitted into the clevis/tang joints. Consequently, there is a relatively high friction associated with the joint. Last, there is a slightly different load path through the joints when the longeron is loaded in tension versus compression.

MSC Nastran ${ }^{\circledR}$ is the modeling tool used to create a finite-element (FE) model with the topology shown in Fig. 4. There are three distinct segments of the model: 1$)$ a middle segment with a region of constant cross-section $(0.5$ inch-square for the straight longerons and 0.59 inch-square for the tapered longerons), 2) the clevis and tang ends which model the joint region, and 3) a section that provides the transition from the square cross-section to the end segments. The clevis and tang regions are the same for both straight and tapered longerons. The longeron is modeled using 2-node beam elements and 2-node rod elements. Beam and rod elements were chosen to keep the model simple. The rod elements are located outboard of the pins (see Fig. 4) and are used to model the different tension versus compression load paths. There are two rod elements at each end, one to model the compression axial stiffness, and one to model the tension axial stiffness (a beam element is coincident with the rod elements to provide bending stiffness). With the exception of the pin friction, all the attributes discussed previously are incorporated into the model. The joint free-play and non-linear stiffness is combined into a single non-linearity

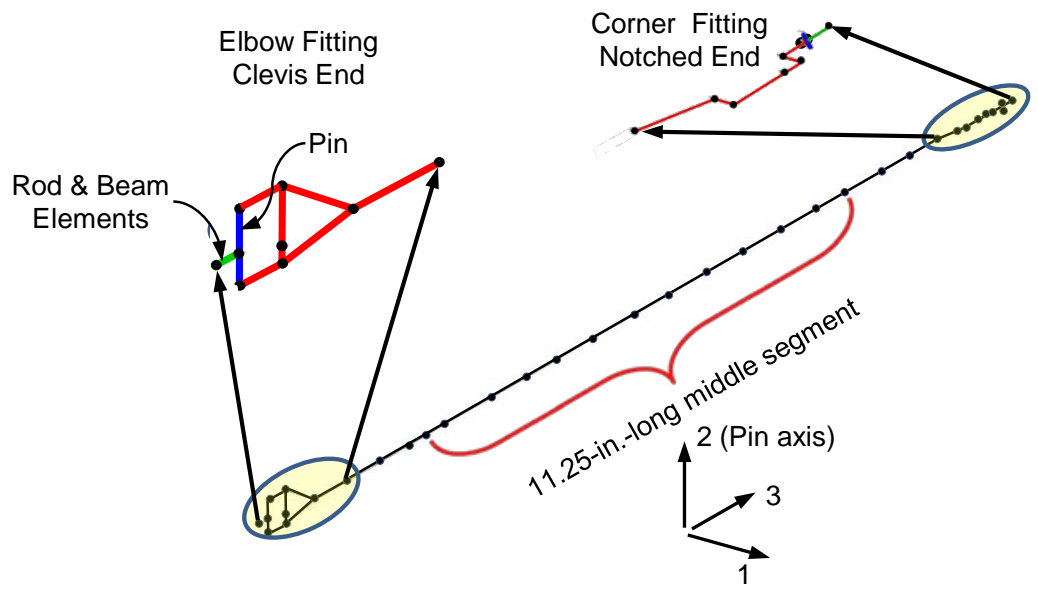

Figure 4. Longeron finite-element model. 
call deadband. The buckling response is produced by restraining the corner end and applying a displacement at the elbow end. Although the model is relatively simple, the analysis incorporates large deflections (buckling) and nonlinear material properties to replicate the deadband and asymmetric load paths.

\section{Longeron Testing}

Tests are conducted on ten straight longerons and eight tapered longerons to provide calibration and validation data, respectively. For the straight longerons, axial stiffness tests and elastic buckling tests are performed. For the tapered longerons, the buckling response would exceed the yield strength of the longeron causing damage. Therefore, only axial stiffness tests are performed. The test set-up is shown in Fig. 5. The longeron is mounted vertically in a load machine. An elbow fitting fixture is attached to the cross-head of the load machine, and a corner fitting fixture is attached to the ram of the load machine. For this test, the cross-head is held fixed and the load is applied through the ram i.e.; the load is applied through the corner fitting end of the longeron. Fixtures are designed to provide a pinned-pinned end condition that mimics the end conditions of the longeron when mounted in a single bay of the truss. To minimize any hysteresis caused by the longeron mounting system the end fixture to load machine interfaces are preloaded, using spiral washers. The zero strain-state of the longeron is established when the longeron is pinned in the upper fixture and is allowed to hang free (i.e. the lower fitting is not attached). Measurements include axial load, ram displacement, axial displacement between the corner fitting fixture and elbow fitting fixture, longeron lateral displacement in two planes, longeron axial strain, and longeron bending strain in two planes. The axial load and ram displacement (stroke) are provided by the load machine's instrumentation system. To measure longeron axial displacement, an extensometer is configured to measure the displacement between the elbow and corner fitting fixtures (a positive end displacement produces a tensile longeron reaction load; a negative end displacements produce a compressive longeron reaction load). Three strain-gage bridges are installed on each longeron as described in Ref. 11. For the straight longerons, one axial bridge is located at 9.75 inches from the center of the longeron elbow pin hole, configured in a full Poisson bridge configuration. Two bending-bridges, one in each bending plane, are located at 15.75 inches from the elbow fitting pin, configured in a full bending bridge configuration. For the tapered longerons the bending gages are located at 12.25 inches from the center of the longeron elbow pin hole. The gages on the tapered longerons are configured to measure axial surface strains.

For the straight longerons, three sub-tests are performed. First, an initial test is performed to characterize the tension and

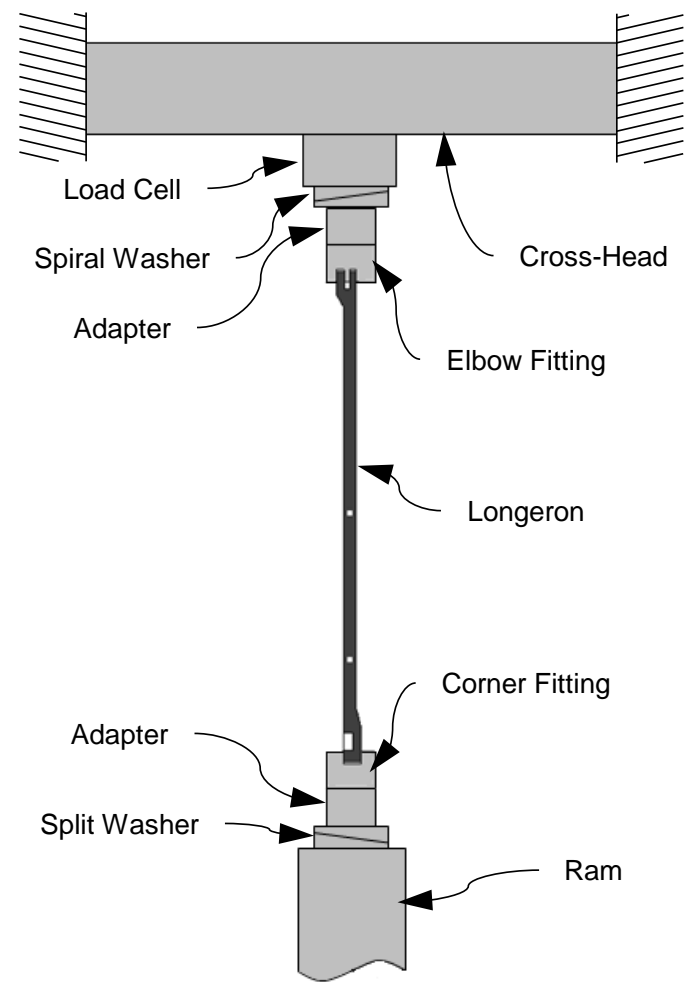

Figure 5. Longeron test set-up. compression stiffness properties of the longeron. Second, a set of three buckling runs are performed to establish the buckling characteristics. Third, the stiffness test is repeated to evaluate repeatability.

The stiffness test is a displacement-controlled test that involves cycling the longeron between tension and compression. To protect the longerons, the maximum and minimum loads are set to not exceed \pm 1000 lbs. (approximately 65\% of the predicted pin/pin buckling load). The stiffness test consists of three compression/tension cycles. Following the stiffness test, the controller is set up for the buckling test. Similar to the stiffness test, the buckling test is displacement controlled and involves compressing the longeron from $200 \mathrm{lbs}$. tension to $1000 \mathrm{lbs}$. compression. At $1000 \mathrm{lbs}$. of compression the displacement rate is slowed and held constant until the longeron buckles and the displacement reached a preset maximum limit. The limit is based on maintaining the surface strain of the longeron below the yield limit of the material (no detrimental yielding). Once the maximum displacement is reached, the ram is stopped. Following a post-buckling hold, the displacement is reduced at a constant rate until the load is reduced to zero. The buckling test for each longeron consisted of three buckling cycles. Following the three buckling cycles, another stiffness test is performed on each longeron in order to determine if the stiffness changed. This final stiffness test consists of an additional three compression/tension load cycles performed using the same procedure as the first stiffness test.

4

American Institute of Aeronautics and Astronautics 
For the tapered longeron, only one test is performed to characterize the stiffness properties of the longeron. The procedure for the straight longeron is repeated for the tapered longeron except the load range is increased to \pm 2500 lbs.

A plot of the typical straight-longeron stiffness characteristics, reaction load versus end displacement, is shown in Fig. 6. The stiffness characteristics are consistent with a revolute jointed system ${ }^{12}$. The stiffness is bi-linear away from a zero load condition (different tension and compression stiffness). Within approximately $\pm 200 \mathrm{lbs}$. of load, the stiffness is non-linear. Two types of non-linearity are observed. The first is free-play due to the pin/hole clearance in the joints. The second is a non-linear stiffness due to the contact between the pin and hole of the joints. Finally, the data shows a slight hysteresis, most likely due to micro-slipping in the joint and material losses.

A plot with typical reaction load versus end displacement results from a buckling load cycle is shown in Fig. 7. Superimposed on the plot are the predicted (eigenvalue analysis) buckling limits for pinned/pinned and fixed/fixed longeron configurations; dashed-dot lines in Fig. 7. At a load beyond the pinned/pinned buckling limit, the longeron begins to 'buckle'. Quotes are used to indicate that this is not a true pinned/pinned or fixed/fixed buckling. Initially, the load loss is due to micro-slipping occurring in the joint. At this point, bending is occurring in a plane approximately $45^{\circ}$ from the plane that contains the pin axis of rotation (plane 23, see Fig. 4). As the end displacement is increased, micro-slipping continues until maximum load is reached. Beyond this point, a small increase in displacement causes a sudden release in the joint. The longeron's bending rapidly increases and rotates to the plane orthogonal to the pin axis (plane 31). This occurs with a corresponding loss of load to a level closer to the pinned/pinned configuration. This event is termed a 'snap'. For the purpose of these tests, the end displacement and value of load at the point of maximum compressive load is defined as the buckling limit.

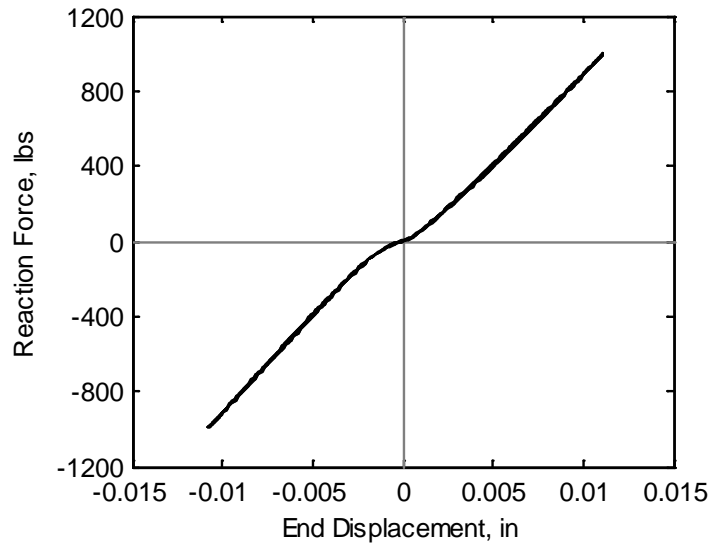

Figure 6. Typical straight-longeron stiffness test result.

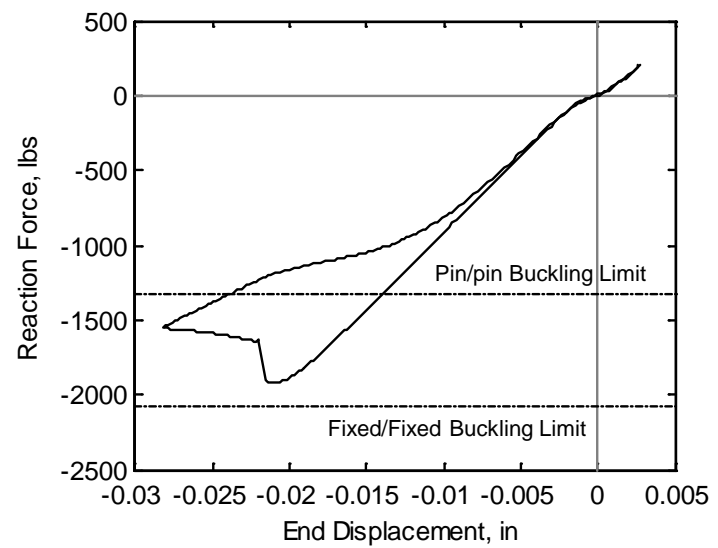

Figure 7. Typical straight-longeron buckling test result.

Data from ten straight-longeron tests (stiffness and buckling) are combined to generate an average, maximum, and minimum responses (load and strain) shown in Fig. 8. The load, axial strain, bending strain in the 31-plane, and bending response in the 23-plane are shown in (a), (b), (c), and (d), respectively. The 31-bending plane is bending in a plane that contains the pin axis of rotation, whereas 23-bending plane is the plane orthogonal to the pin axis.

The data are processed in two parts. Data from either the stiffness tests or buckling tests within a load range of \pm 1000 lbs. are processed together. However, data collected from each load cycle of these tests are treated as independent datasets and processed to generate basic statistical information (averages, standard deviation, maximums, and minimums) about the responses (load, displacement, and strain) in the load range of \pm 1000 lbs. (for a total of 90 load cycle datasets). Similarly, data from the buckling tests, beyond a compressive load of 1000 lbs., are treated separately in a two-step process. First, the data for each longeron are processed to compute the average, maximum, and minimum values of the responses. Second, the average, maximum, and minimum responses from each of the 10 longerons is processed together to give an aggregate average, standard deviation, maximum, and minimum response. Maximum/minimum ranges are used in instead of 2- or 3-sigma bounds because the distributions of the data in the different regions of the response curves appear to be different. For example, in the deadband region, the distribution appears to be close to a uniform distribution. However, in the linear region the distribution appears to be normal. In the buckling region, the distribution is close to a log-normal distribution. Also, the variability in the end displacement for the nearly discontinuous 'snap' makes the statistical treatment of the response in this region difficult. 


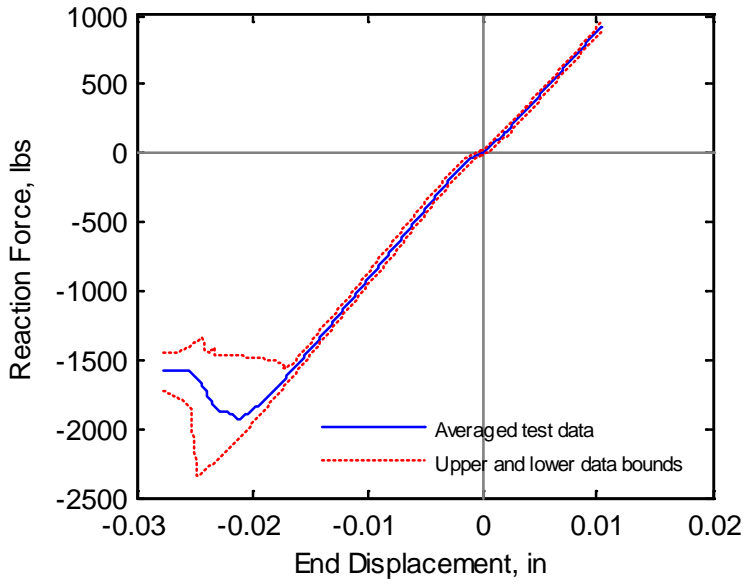

(a) Load

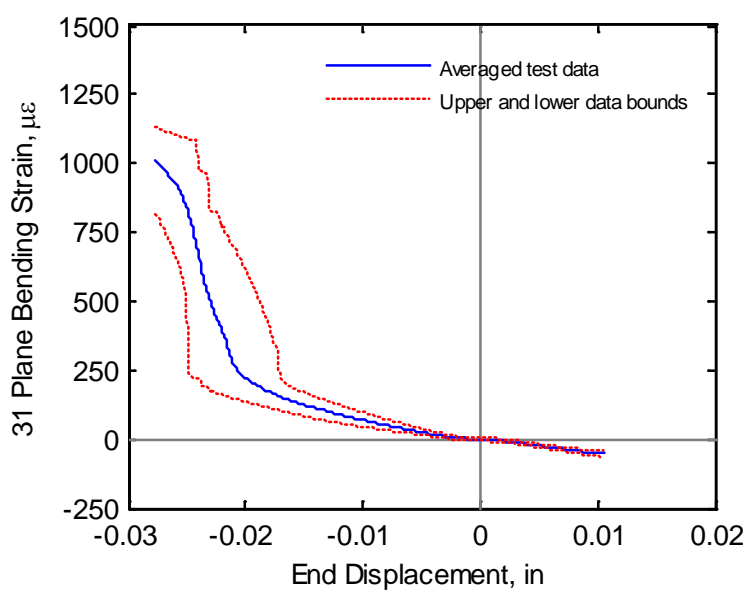

(c) 31-Plane bending strain

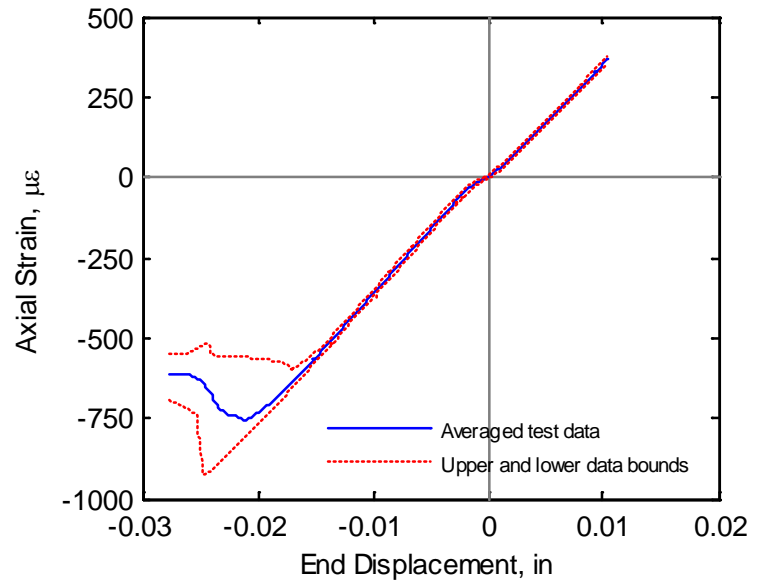

(b) Axial strain

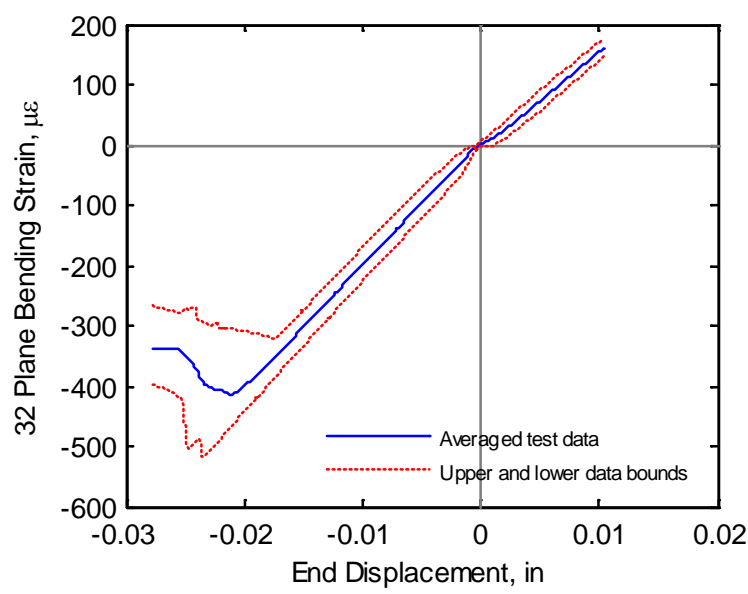

(d) 23-Plane bending strain

Figure 8. Mean test response.

In general, the variation of the data is small through the pre-buckling region of response; the variation is approximately two to three times the standard deviation of the data in this region. However, when the displacement is sufficient to initiate the 'buckling' response, the data ranges increase drastically. 'Buckling' can occur in a displacement range of approximately -0.015 to -0.025 inches. This means that the 'snap' events may occur anywhere within this range. The interpretation of the mean response through this region is subjective since it is the average of many near-discontinuous data sets. Also, the impact of the 'snap' events on the axial strain and 23bending strain response is similar to the load response. However, for the 31-bending response, the impact of the 'snap' is to move the knee in the response between -0.015 and -0.025 inches of displacement. This reflects the rotation of the bending direction from between the 31 and 23 planes to be more aligned with the 31-plane.

Test results and the processing of the tapered longerons is similar to the straight longerons with the exception that only a stiffness test is performed and the load range is $\pm 2500 \mathrm{lbs}$. Eight tapered longerons are processed resulting in 24 load cycle datasets available for averaging. The results of the processing are presented in the validation section. 


\section{Model Calibration and Validation Strategy}

A flow-down of requirements from the mast assembly, to single bay, to the longerons, leads to the objective of the longeron model, which is to predict the longeron's response to axial end displacement in both tension and compression. Specifically, there are four responses of interest: load, axial strain, and bending strain in two planes. It follows that the objective of the calibration effort is to determine a model and set of model parameters that reconcile the mean response of the model with the mean response from test. To this end, the calibration strategy shown in Fig. 9 was developed. The strategy begins by using a baseline FE model to study the relevant modeling assumptions, parameters, and parameter distribution functions that affect the target responses. With the parameters and distributions defined, a probabilistic model for the parameters is used to create parameter values that are used in the FE model to develop a family of response predictions (database). This database is used to evaluate calibration metrics to determine whether the FE model and parameter probabilistic model are valid. Validity at this point is judged based on the ability of the model to explain measured values. If the model is not valid then a revised $\mathrm{FE}$ model and/or set of parameters are determine and re-evaluated. This iteration is continued until an appropriate set of parameters and distributions are found that satisfy the calibration metric. Once a valid model is found, the associated database is used along with an objective function to determine a set of parameters that minimize the difference between the test and analysis. These steps are discussed in more detail in subsequent sections.

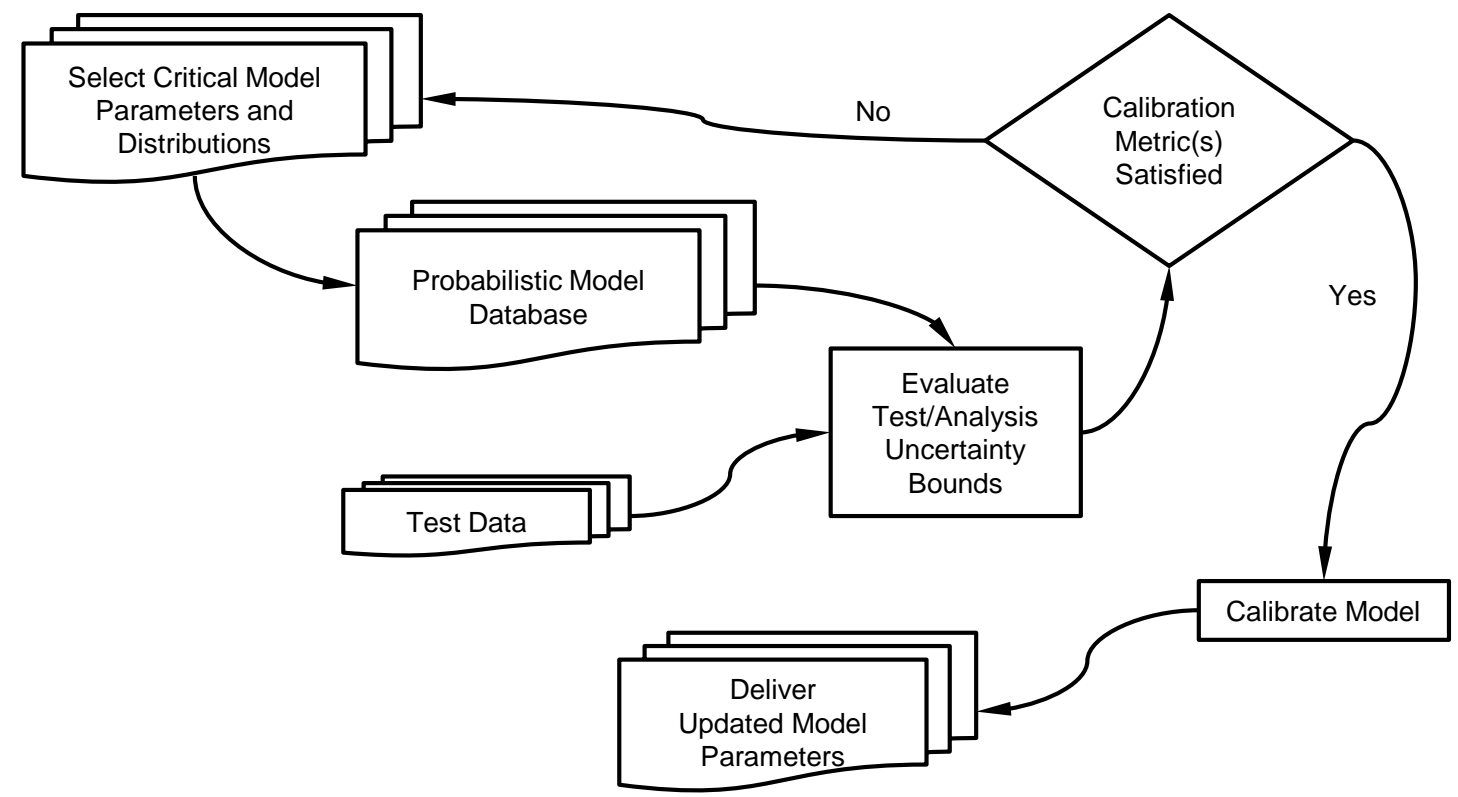

Figure 9. Calibration process.

\section{Parameter Selection.}

With a baseline FE model at hand, determining the important parameters to use in the calibration is not a trivial task. The number of parameters is potentially large given the uncertainty in the geometry (eccentricity), deadband, boundary conditions, load path asymmetry, and modeling of the corner and elbow segments. Analysis of Variance and numerous 'brute-force' (analyzing the model's response to changes in single parameters) sensitivity studies were performed to understand the first-order effects of various modeling assumptions. The combination of these sensitivity studies with the analyst's knowledge of the model is used to determine an initial set of parameters. For the parameters considered, there is either no information or limited information about parameter distributions. Therefore, in all cases a uniform distribution function, which is the least informative distribution function, is used to model parameter uncertainty. Parameters are defined in terms of a nominal value, lower bound, and upper bound.

\section{Calibration Metrics for Parameter Adequacy Assessment}

To begin the calibration process an initial set of parameters and distributions functions are used to create a family of $N$ equally probable model responses which are stored in a database. In this application, parameter values are generated using a Halton ${ }^{13}$ deterministic sampling technique. From the perspective of the user, it is important to 
know the probability of being able to reconcile measured data with predictions. To this end, let $y(x, p)$ be a scalar response function (e.g, load or strain) defined as a function of displacement $x$ and a vector of parameters $p$. Furthermore, let $\bar{\sigma}=\max _{\forall p} y(x, p)$ be the maximum response value over all parameter variations, and let $\underline{\sigma}=$ $\min _{\forall p} y(x, p)$ be the minimum response value. Using these definitions and $N$ FE model solutions corresponding to equally probable parameter vectors, a calibration metric can be established to bound the probability of test values falling inside the analysis bounds as;

$$
M_{1}=\operatorname{Prob}\left(\underline{\sigma}<y_{c}(x)<\bar{\sigma}\right) \gg \frac{1}{N}
$$

where $y_{c}(x)$ is the experiment response. Note that $N$ controls tightness of the bounds and also the number of FE model solutions required. Simply stated, if the experimental data fall within the predicted analysis bounds, the probability of finding a reconciling solution is $>>1 / N$. Adequacy of the parameter set and the FE model is established at this point. Otherwise, the model is not likely to be reconcilable and a revised parameter set and FE model needs to be developed. Note that in Eq. (1), the experimental response of interest can be a mean value or an upper/lower bound.

Once a FE model and probabilistic model for the parameters that satisfies the calibration criteria are found, the next step is to determine a parameter set that best reconciles the analysis with test. A straight forward objective function to reconcile the model would be to compute the prediction error between the analysis and measured responses. Unfortunately, there are aspects of the test responses that are not modeled in the analysis. Specifically, the micro-slip in the joints that leads to the 'snap' event and the non-linear contact stiffness in the joint that leads to a non-linear response between $\pm 200 \mathrm{lbs}$ are not modeled. Given the model's limitations, the focus of the reconciliation effort is limited to end displacements that produce reaction loads from $200 \mathrm{lbs}$ of compression to $80 \%$ of the buckling limit and from $200 \mathrm{lbs}$ to $1000 \mathrm{lbs}$ of tension. Within these displacement ranges, the following metrics are used as components of the objective function.

- The relative error between the analysis and test slopes of the load versus displacement response in compression and tension (axial stiffness).

- The relative error between the analysis and test slopes of the axial strain versus displacement response in compression and tension.

- The relative error between the analysis and test slopes of the bending strain in the plane (23) containing the pin axis versus displacement response in compression and tension.

- $\quad$ A normalized root mean square (rms) error between the load versus displacement response.

- A normalized rms error between the bending strain in the plane orthogonal to the pin axis (31) versus displacement response.

- A normalized rms error between the bending strain in the plane containing the pin axis (23) versus displacement response.

A reconciling solution $\hat{p}$ for the parameter vector minimizes all 6 metrics.

A final step in the calibration process deals with adjustments to values used to define the parameter distributions functions. For example, in this problem, parameters such as deadbands, areas, etc. are assumed to be uniformly distributed between bounds, often selected with little a priori information. Initially, the problem assumes that parameter $p_{i}$ varies uniformly between bounds defined by $d_{i} \triangleq\left[\begin{array}{ll}l_{i} & u_{i}\end{array}\right]$, where $l_{i}$ and $u_{i}$ are the upper and lower bounds of parameter $p_{i} *$. In the following, subscripts are used to refer to elements of a vector. From an engineering viewpoint, it is important that the FE model along with the parameter uncertainty model be predictive in the mean. That is the mean response of the analysis, denoted by $\bar{y}(x, p)$, must be close to the measured mean response $\bar{y}_{c}(x)$. Note that the mean response for the analysis is computed by averaging the response predicted by using many realizations of the parameter vector $p$. However, realizations of the parameter vectors depend on the parameter bounds $p(d)$. Consequently, the optimization problem seeks to find a vector $d=\left\{\begin{array}{llll}d_{1} & d_{2} & \cdots & d_{m}\end{array}\right\}$ to minimize the error difference between the mean analysis response and the mean test response

$$
J(x, p)=\underset{d \in \mathbb{R}}{\operatorname{argmin}}\left\{\left|\bar{y}(x, p)-\bar{y}_{c}(x)\right|: l_{i}^{o}<l_{i}<\hat{p}_{i}, \hat{p}_{i}<u_{i}<u_{i}^{o}, i=1,2, \ldots, m\right\}
$$

\footnotetext{
${ }^{*}$ In the following, subscripts are used to refer to elements of a vector.
} 
where the initial upper and lower bound values are denoted as $l_{i}^{o}$ and $u_{i}^{o}$, respectively, the number of parameters is denoted by $m$, and the vector $d$ is defined over the set of real numbers $\mathbb{R}$ within the constraints. A subtle but important feature is the fact that constraints are defined using the reconciling solution $\hat{p}$.

\section{Calibration Results}

\section{Initial Model Calibration}

Calibration efforts begin by selecting model parameters for the baseline FE model. As discussed earlier, the initial parameters selection depended on initial sensitivity studies and analyst judgment. The twelve initial parameters with their associated uncertain ranges are shown in Table 1 . These initial parameters reflect an uncertainty in the modeling of the clevis and tang region of the model. The rod parameters (tension and compression) are cross-sectional areas of the rods used to account for different tension and compression load paths. The corner and elbow location parameters are the locations of the nodes in the clevis and tang regions, and they are used to account for the eccentricity. The deadband parameters are used to account for the non-linear behavior in the deadband region of response. They are expressed as strain, and they define a near zero portion of a stress/strain curve used to define the rod element modulus.

Using these parameters and their distribution functions, a family of 492 model response solutions is created. The calibration metric $M_{1}$, in terms of the upper and lower model bounds $\bar{\sigma}$ and $\underline{\sigma}$, respectively, along with the test response are plotted in Fig. 10. With this sample size, the probability of being able to reconcile the test with the analysis when the test mean is outside the model bounds is approximately $0.2 \%$. While the analysis bounds encompass the test data for the load, axial strain, and 31-plane bending response (Fig. 10(a), (b), and (c)), the test mean for the 23-plane bending strain is outside the analysis bounds (Fig. 10(d)). Therefore, for this model and associated parameter assumptions, it is unlikely that one would be able to find parameter values that would reconcile the analysis with test for all the responses of interest. This finding prompted another look at the FE model, parameter set, and uncertainty models to determine a more suitable parameter set.

Table 1. Initial Model Parameter Description

\begin{tabular}{|c|c|c|c|c|c|}
\hline \multicolumn{3}{|c|}{ Parameter } & Nominal & Upper Bound & Lower Bound \\
\hline 1 & Bulk Modulus & $\mathrm{lb} / \mathrm{in}^{2}$ & $10.0 \mathrm{E}+06$ & $11.0 \mathrm{E}+06$ & $9.0 \mathrm{E}+06$ \\
\hline 2 & Tension rod area & in $^{2}$ & 0.03 & 0.05 & 0.01 \\
\hline 3 & Compression rod area & in $^{2}$ & 0.30 & 0.50 & 0.10 \\
\hline 4 & $\Delta$ Tang nodes location & in & 0.00 & 0.00 & -0.02 \\
\hline 5 & $\Delta$ Clevis nodes location & in & 0.00 & 0.10 & -0.10 \\
\hline 6 & Tension deadband strain & in/in & $1.06 \mathrm{E}-03$ & $2.21 \mathrm{E}-03$ & 0.0 \\
\hline 7 & Compression deadband strain & in/in & $1.88 \mathrm{E}-03$ & 2.97E-03 & 800E-06 \\
\hline 8 & Clevis pin torsional stiffness, $\mathrm{J}$ & in $^{4}$ & 3.83E-03 & 38.3E-03 & 3.83E-06 \\
\hline 9 & Tang pin torsional stiffness, J & in $^{4}$ & 3.83E-03 & 38.3E-03 & 3.83E-06 \\
\hline 10 & $\begin{array}{l}\text { Modulus for the notch offset } \\
\text { elements }\end{array}$ & $\mathrm{lb} / \mathrm{in}^{2}$ & $100 \mathrm{E}+06$ & $120 \mathrm{E}+06$ & $80.0 \mathrm{E}+06$ \\
\hline 11 & $\begin{array}{l}\text { Modulus for the tang } \\
\text { boundary beam }\end{array}$ & $\mathrm{lb} / \mathrm{in}^{2}$ & $10.0 \mathrm{E}+06$ & $12.0 \mathrm{E}+06$ & $8.00 \mathrm{E}+06$ \\
\hline 12 & $\begin{array}{l}\text { Modulus for the clevis } \\
\text { boundary beam }\end{array}$ & $\mathrm{lb} / \mathrm{in}^{2}$ & $10.0 \mathrm{E}+06$ & $12.0 \mathrm{E}+06$ & $8.00 \mathrm{E}+06$ \\
\hline
\end{tabular}




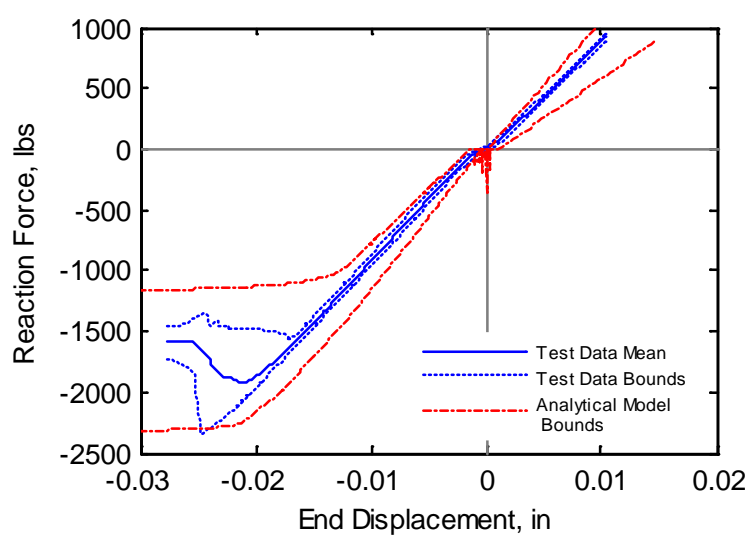

(a) Load

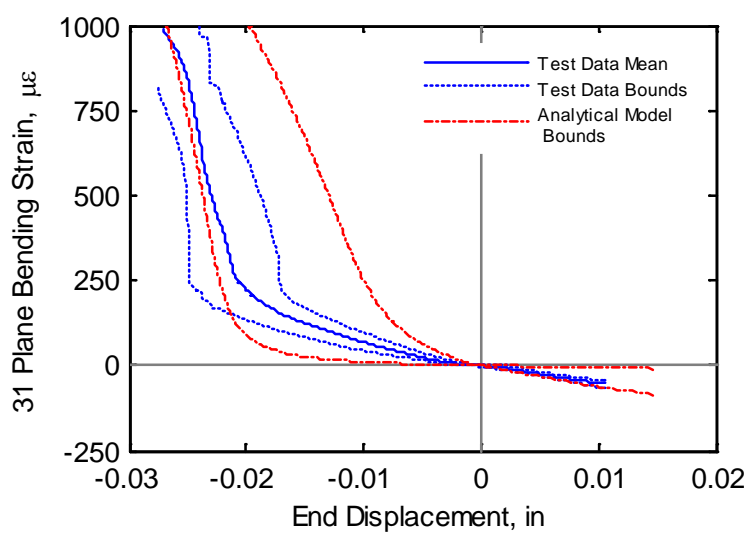

(c) 31-Plane bending strain

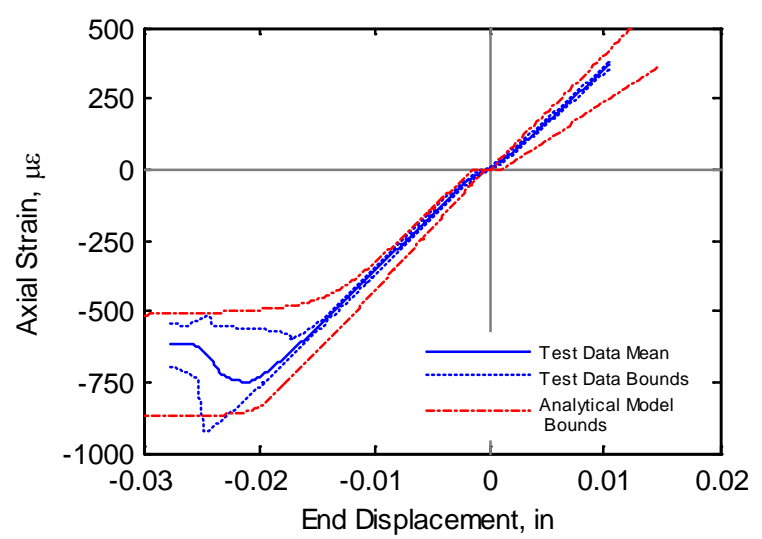

(b) Axial strain

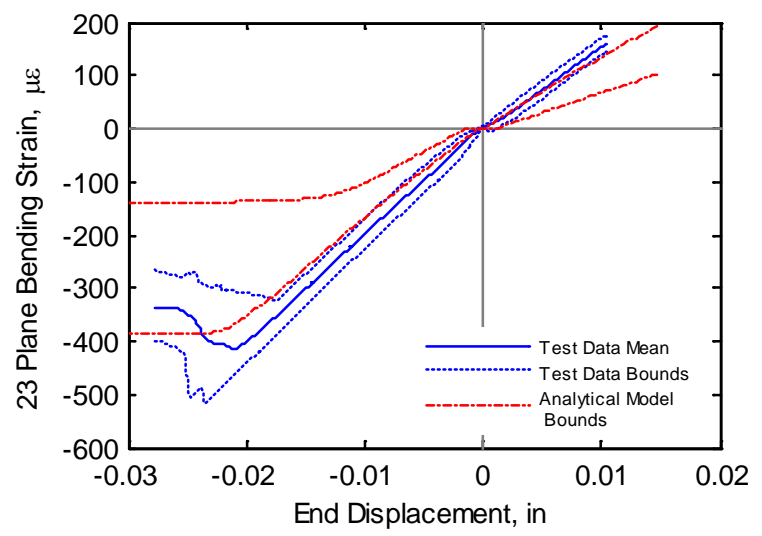

(d) 23-Plane bending strain

Figure 10. Initial parameter set model bounds.

\section{Intermediate Model Calibration}

A second search for a revised parameter set involved an in-depth review of the modeling assumptions, techniques, and parameter selection. Roughly 14 different models of the straight longeron were assessed. Each one involved assessing different modeling approaches. For example; in the original model, to account for the different tension and compression axial load paths, non-linear rod elements were added at either end of the longeron. One rod reacts in tension and the other reacts in compression. This observation led to the hypothesis that the bending response is also non-linear. Therefore, in one of the models assessed, the boundary beams were made non-linear inorder to assess this hypothesis. Modeling parameters and ranges were also challenged. Extensive sensitivity studies were performed on thirty parameters dealing with the model's element properties, geometry, and boundary conditions. These studies were made difficult by the fact that many of these parameters are strongly coupled. Also, instances occur where the response is insensitive to one parameter unless a second parameter is within a specified range such as the interaction between the clevis region geometry and the area moment-of-inertias of the boundarybeams. Within the boundary assumptions of one model, the bending response is relative insensitive to the values of the boundary-beam inertia unless the eccentricity, define by the clevis geometry, is within a specific range. Within this range, small changes in the boundary beam inertias have a large effect on the bending response. In most of these studies the calibration metric was used as a tool to assess the impact of changes on the model bounds. In the end, it was determined that the initial boundary condition assumptions were over-constraining the solution. By reassessing the boundary conditions, a set of model parameters could be formulated that provide for a model that satisfies the calibration metric. 


\section{Final Model Calibration}

The final set of parameters is similar to the initial set in that the parameters reflect uncertainty of the clevis and tang region of the model. However, in performing the sensitivity analyses of the previous step, a significant increase in the knowledge of the model's behavior was obtained. In particular, this prompted the elimination of some parameters, the addition of other parameters, and a better understanding of the interaction and effective range of the parameters. The final parameter set, shown in Table 2, includes nine parameters as opposed to 12. Although similar regions are affected, the parameters themselves are different as well as their corresponding bounds. Using these parameters, a family of 555 solutions is created. Results for the calibration metric $M_{1}$ in terms of the upper and lower model bounds $\bar{\sigma}$ and $\underline{\sigma}$, respectively, along with the test response are plotted in Fig. 11. With this sample size, the probability of being able to reconcile the test with the analysis when the test mean is outside the model bounds is less than $0.2 \%$. In each of the responses, the test mean is now captured by the model bounds. Also for all but the 31-bending strain, the model bounds capture the test bounds for the tension response and compression response up to approximately -0.015 inches of displacement.

\section{Table 2. Revised Parameters}

\begin{tabular}{|c|c|c|c|c|c|}
\hline \multicolumn{2}{|r|}{ Parameter } & & Nominal & Upper Bound & Lower Bound \\
\hline 1 & Tension rod area & in $^{2}$ & 0.0208 & 0.0248 & 0.0168 \\
\hline 2 & Compression rod area & in $^{2}$ & 0.0486 & 0.0636 & 0.0336 \\
\hline 3 & Tension deadband strain & in/in & 1.18E-03 & $1.58 \mathrm{E}-03$ & 680E-06 \\
\hline 4 & Compression deadband strain & in/in & $-1.88 \mathrm{E}-03$ & $-1.38 \mathrm{E}-03$ & $-2.58 \mathrm{E}-03$ \\
\hline 5 & Modulus & $\mathrm{lb} / \mathrm{in}^{2}$ & $10.8 \mathrm{E}+06$ & $11.0 \mathrm{E}+06$ & $10.4 \mathrm{E}+06$ \\
\hline 6 & Tang area moment of inertia $\mathrm{I}_{1}$ & in $^{4}$ & 270.0E-06 & $1.00 \mathrm{E}-03$ & $50.0 \mathrm{E}-06$ \\
\hline 7 & Tang area moment of inertia $\mathrm{I}_{2}$ & in $^{4}$ & 520.0E-06 & 890E-06 & 360E-06 \\
\hline 8 & Clevis area moment of inertia $I_{1}$ & in $^{4}$ & $500.0 \mathrm{E}-06$ & $5.0 \mathrm{E}-03$ & 50.0E-06 \\
\hline 9 & Clevis area moment of inertia $\mathrm{I}_{2}$ & in $^{4}$ & 200.0E-06 & $1.60 \mathrm{E}-03$ & 100E-06 \\
\hline
\end{tabular}

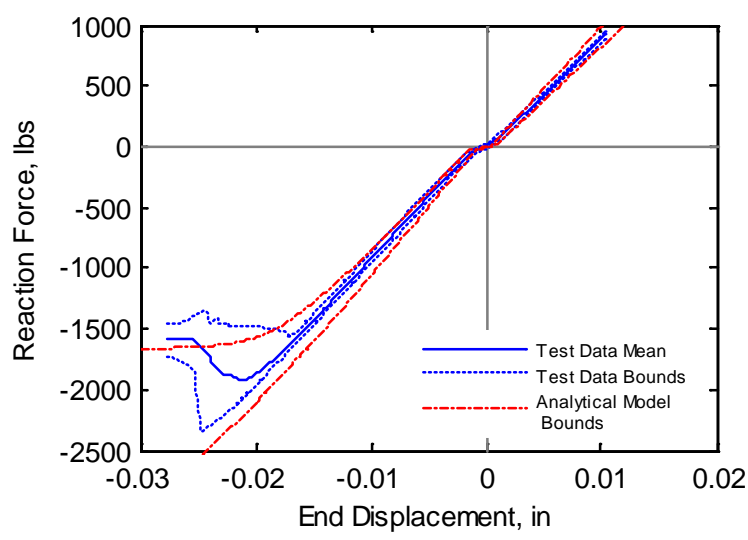

(a) Load

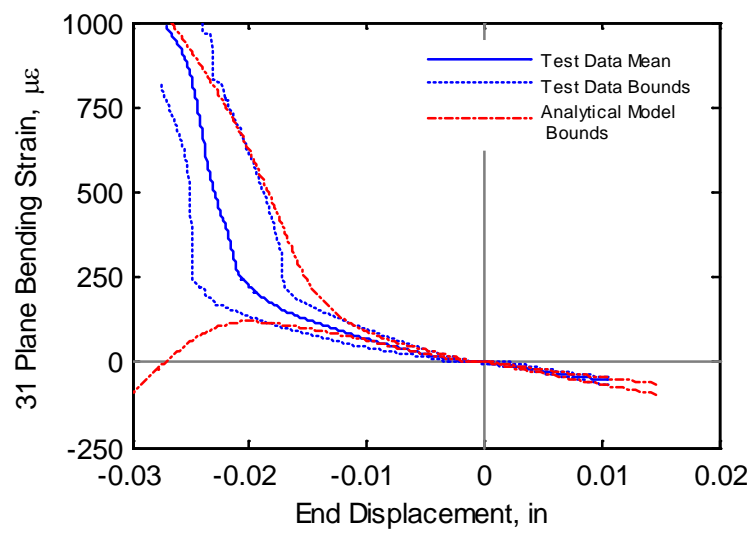

(c) 31-Plane bending strain 


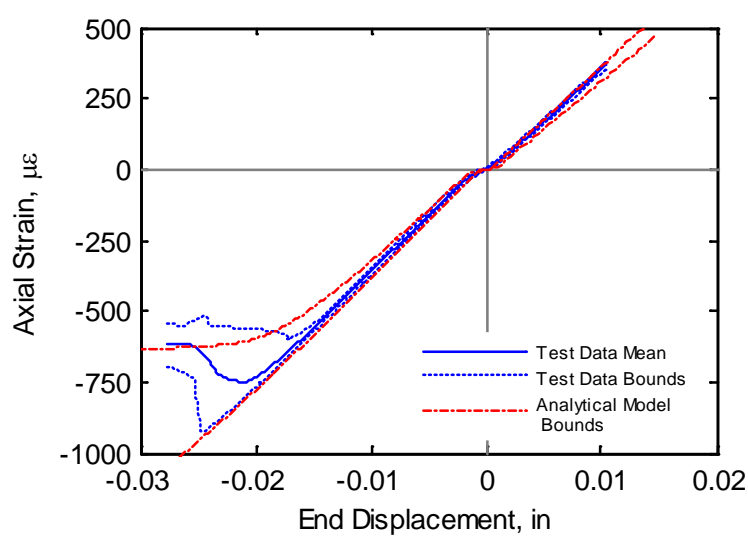

(b) Axial strain

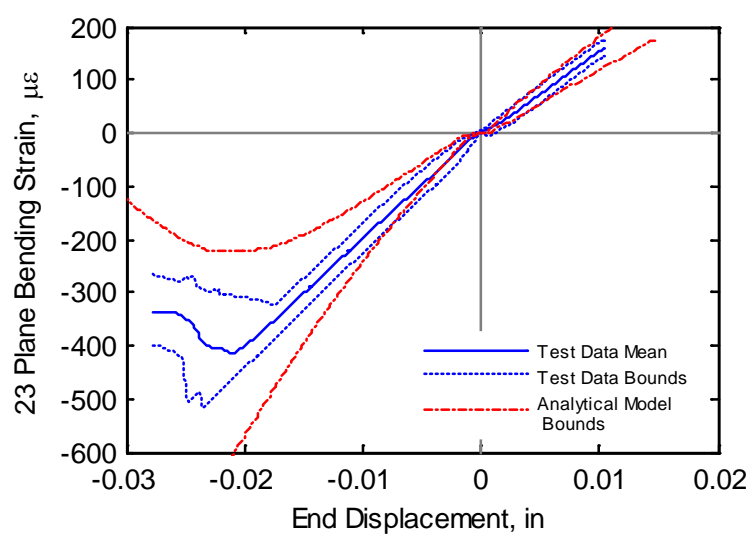

(d) 23-Plane bending strain

Figure 11. Revised parameter set model bounds.

\section{Reconciliation of the Model with Test}

The next step of the calibration is to determine a deterministic parameter vector $\hat{p}$ that best reconciles the analysis with the test mean. This reconciling solution $\hat{p}$ needs to minimize all 6 metrics described in Section III. Optimization can be used to find a solution that minimizes all metrics. However, after searching the database (with 555 solutions), a parameter set, $\hat{p}$, was found that reconciled test with analysis. The reconciling parameter vector is shown in Table 3. For reference, Table 2 provides the original 'nominal' parameters. The mean analytical responses, responses using the reconciling parameters, and test mean responses are shown in Fig. 12.

Table 3. Calibrated Solution

\begin{tabular}{|c|c|c|c|c|c|c|}
\hline \multicolumn{3}{|c|}{ Parameter } & Nominal & $\begin{array}{l}\text { Reconciled } \\
\text { Parameters }\end{array}$ & $\begin{array}{c}\text { Optimized } \\
\text { Upper } \\
\text { Bound } \\
\end{array}$ & $\begin{array}{c}\text { Optimized } \\
\text { Lower } \\
\text { Bound } \\
\end{array}$ \\
\hline 1 & Tension rod area & $\operatorname{in}^{2}$ & 0.0208 & 0.0231 & 0.0248 & 0.0168 \\
\hline 2 & Compression rod area & in $^{2}$ & 0.0486 & 0.0600 & 0.0629 & 0.0453 \\
\hline 3 & Tension deadband strain & in/in & $1.18 \mathrm{E}-03$ & $1.50 \mathrm{E}-03$ & $1.58 \mathrm{E}-03$ & 769E-06 \\
\hline 4 & Compression deadband strain & in/in & $-1.88 \mathrm{E}-03$ & $-2.20 \mathrm{E}-03$ & $-1.38 \mathrm{E}-03$ & $-2.58 \mathrm{E}-03$ \\
\hline 5 & Modulus & $\mathrm{lb} / \mathrm{in}^{2}$ & $10.8 \mathrm{E}+06$ & $10.5 \mathrm{E}+06$ & $10.5 \mathrm{E}+06$ & $10.4 \mathrm{E}+06$ \\
\hline 6 & Tang area moment of inertia $\mathrm{I}_{1}$ & in $^{4}$ & $270.0 \mathrm{E}-06$ & 2.17E-04 & $1.00 \mathrm{E}-03$ & 50.0E-06 \\
\hline 7 & Tang area moment of inertia $\mathrm{I}_{2}$ & in $^{4}$ & $520.0 \mathrm{E}-06$ & 609E-06 & 861.0E-06 & 360E-06 \\
\hline 8 & Clevis area moment of inertia $\mathrm{I}_{1}$ & in $^{4}$ & 500.0E-06 & 3.13E-03 & $5.0 \mathrm{E}-03$ & 50.0E-06 \\
\hline 9 & Clevis area moment of inertia $\mathrm{I}_{2}$ & in $^{4}$ & 200.0E-06 & 5.26E-04 & $1.60 \mathrm{E}-03$ & 100E-06 \\
\hline
\end{tabular}




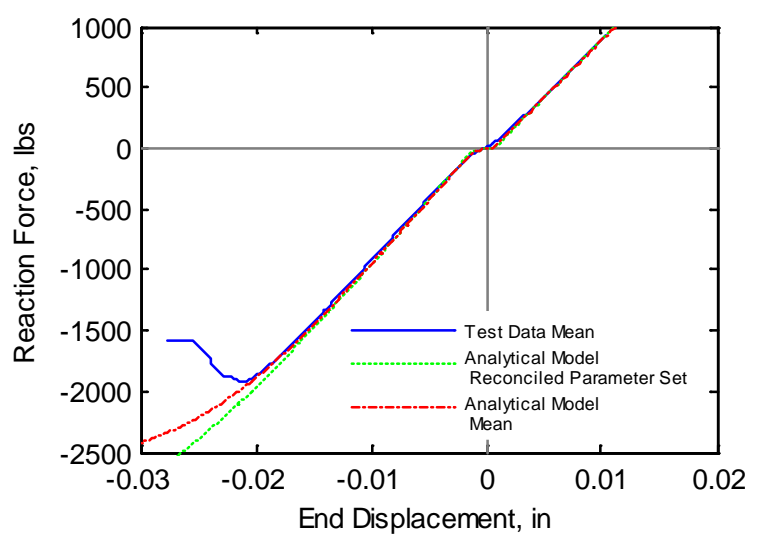

(a) Load

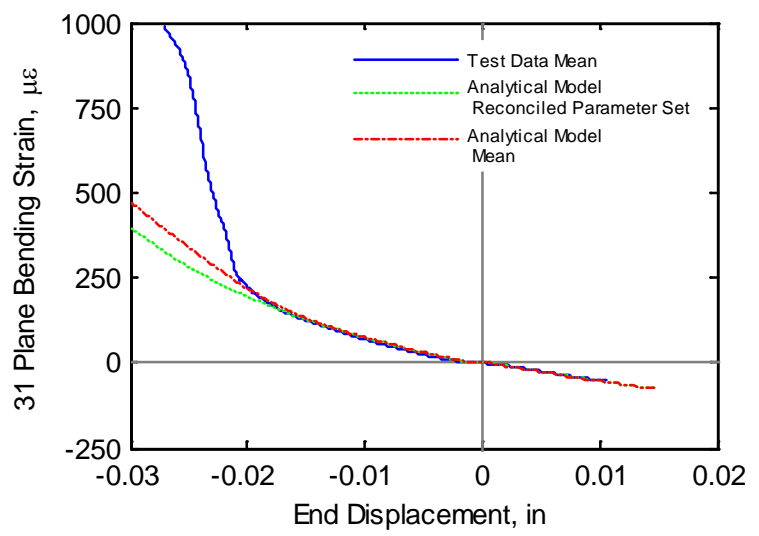

(c) 31-Plane bending strain

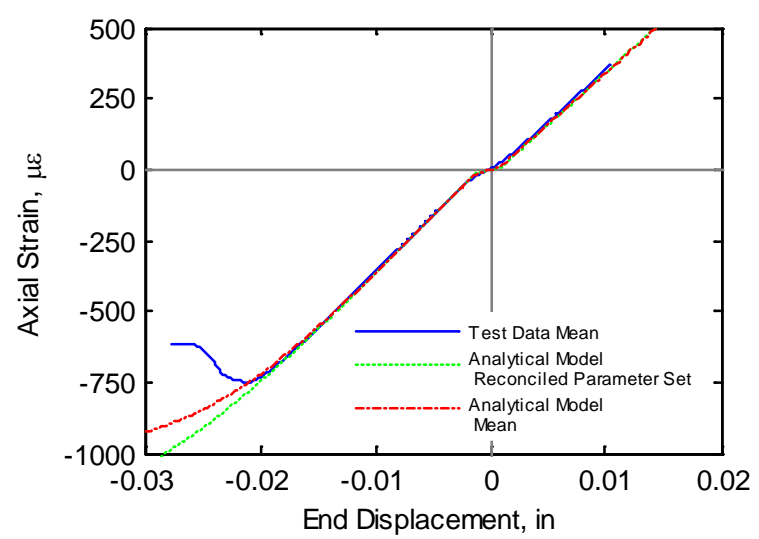

(b) Axial strain

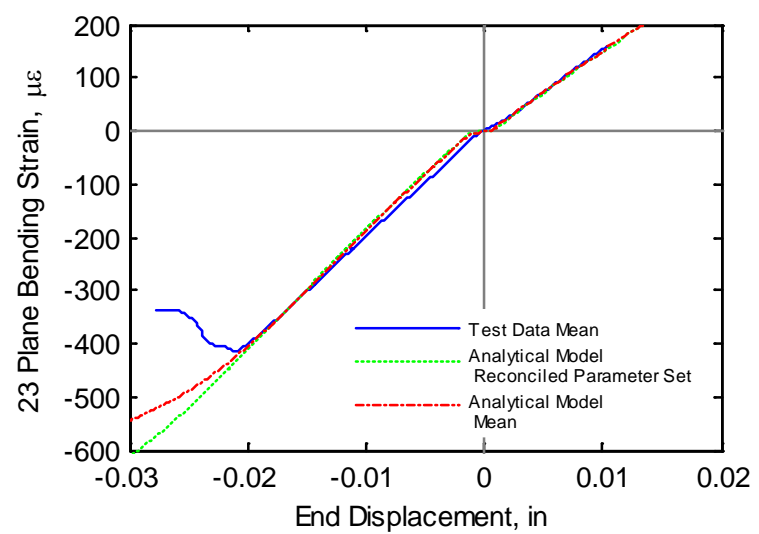

(d) 23-Plane bending strain

Figure 12. Reconciled model response.

The final step of the calibration process is to adjust the distribution function to assure that the mean predicted response, including parameter uncertainty, matches that of test. Recall that the reconciling solution $\hat{p}$ is just one possible realization of the parameter vector. In contrast, this final step seeks to adjust the parameter distributions, which in this problem is just the adjustment of bounds to match the mean test response. In order to optimize the parameter bounds, the problem uses the objective function defined in Eq. (2) with an Extended Radial Basis Function $(\mathrm{ERBF})^{14}$ response surface model instead of the FE model. A response surface model is needed because at each optimization step 100 model predictions are computed to estimate the mean response for the analysis response. If one were to use the FE model directly, the optimization would require a very large number of FE model solutions. Table 3 shows the optimized upper and lower bounds. Note that changes between the bounds of the revised parameters, shown in Table 2, and the optimized bounds, shown in Table 3, are small. This reflects the significant amount of work performed in reassessing the model after the first pass through the process. Figure 13 shows the model bounds in relation to the test. Although the changes in the parameter description are modest, the new bounds provide for a better match between the model bounds and test bounds for the load and axial strain response. The bending strain response bounds are inside the test bounds. Reviewing the differences between the revised and optimized parameters, shows that there is no change in the area moment-of-inertia parameters. These parameters have the biggest impact on the bending response of the model. This indicates that the revised parameters are most likely over-constraining the solution. 


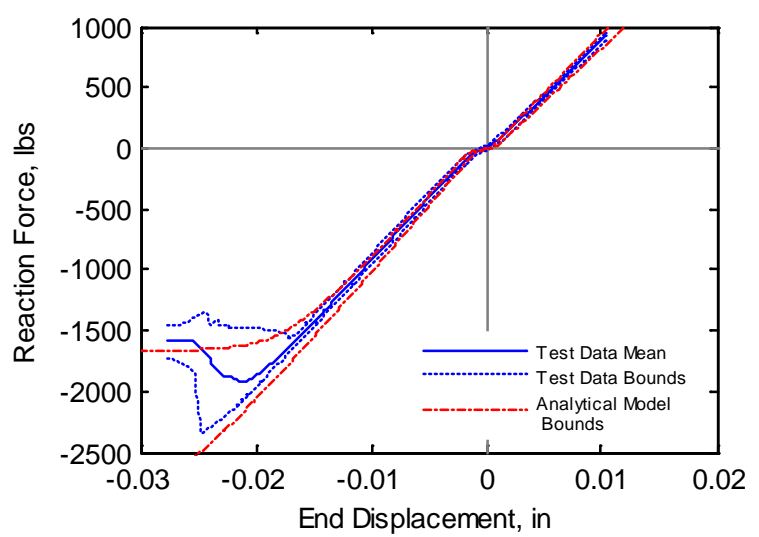

(a) Load

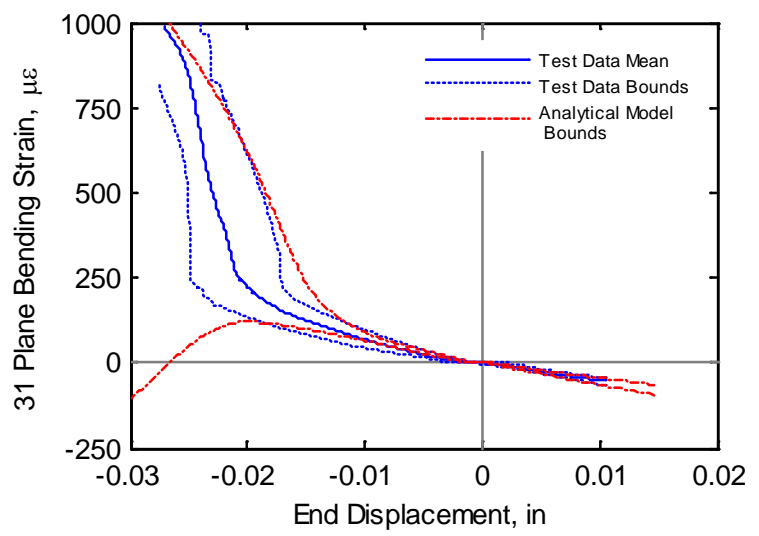

(c) 31-Plane bending strain

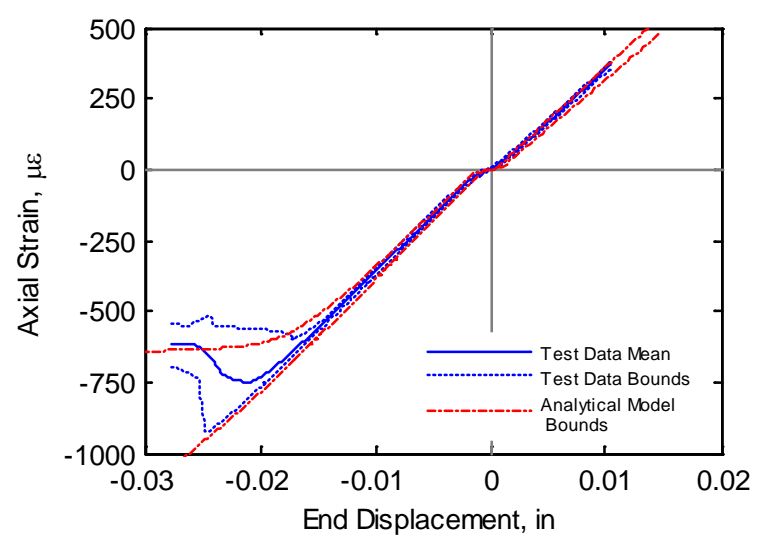

(b) Axial strain

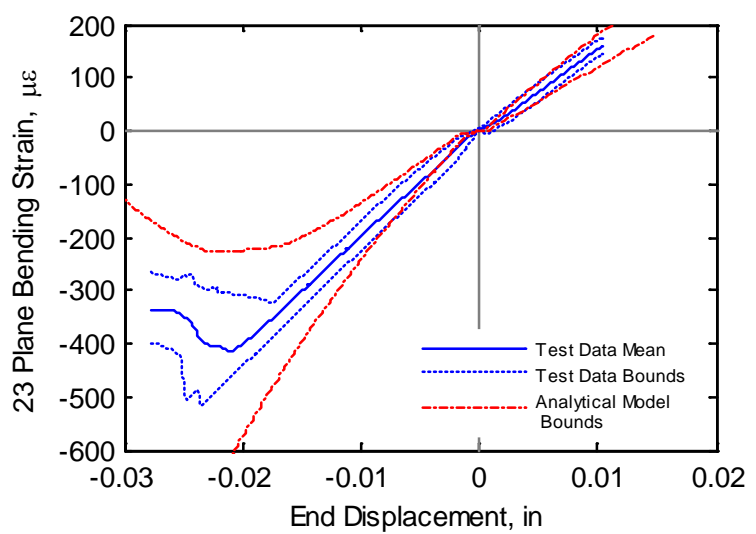

(d) 23-Plane bending strain

Figure 13. Optimized parameter set model bounds.

\section{Validation}

The availability of tapered longerons affords the ability to validate the model developed for the straight longerons. The objective of the validation is to determine whether the properties of the calibrated straight longeron can be used to predict the response of the tapered longeron. Specifically, are the tapered-longeron responses and bounds using the single-longeron calibrated parameters and bounds consistent with test results? Recall that the tapered longerons are similar to the straight longerons with the exception that the middle section of the longeron has a 0.59 inch square cross-section. A finite-element model of the tapered longeron is developed that has the same topology as the straight longeron. The properties of the middle section and the transition section reflect the geometry changes. However, the modeling of the clevis and tang regions is the same as the straight longeron. Testing of eight tapered longerons is performed using the same test set-up as the straight longerons except the tapered longerons do not undergo a buckling test and the stiffness test is performed using load limits of \pm 2500 lbs.

Results from the calibration of the straight longerons, in Table 3, are used with the tapered-longeron model. The probabilistic model of the parameters is used to generate a family of $555 \mathrm{FE}$ model solutions. Figure 14 shows the analysis bounds using the calibrated parameters, the analysis response using the reconciling parameters, and the test responses; model predictions are shown in red and the test results are shown in blue. Intuitively, for a model to be validated it should satisfy the same metrics as those used for calibration. After examining the load and axial strain response shown in Fig. 14(a) and Fig. 14(b), the model responses do not encompass the test data in compression. Nevertheless, closer examination reveals that the slopes of the test mean and analysis solution using the reconciled parameters $\hat{p}$ are similar. The difference in the slopes is less than $6 \%$. Therefore, the axial stiffness is correctly captured. The difference in results is due to a difference in the deadband values between the test and analysis because the tested tapered longerons have a larger deadband than the straight longerons. Also, the reconciled 
analytical bending response in compression is similar to the test response as shown in Fig. 14(c) and Fig. 14(d). However, the test data mean and bounds for bending strain are outside the analysis bounds in tension. Hence, the model is stiffer in tension than the tested longeron. These bending results indicate that the tapered-longeron data failed to validate the model.

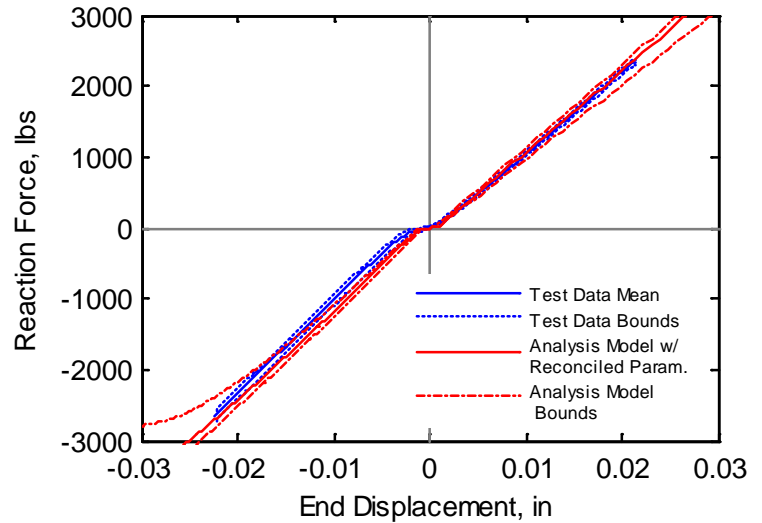

(a) Load

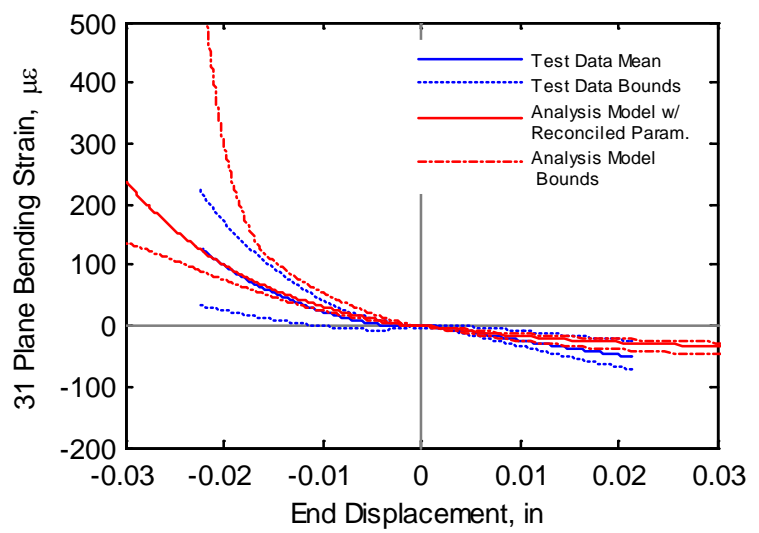

(c) 31-Plane bending strain

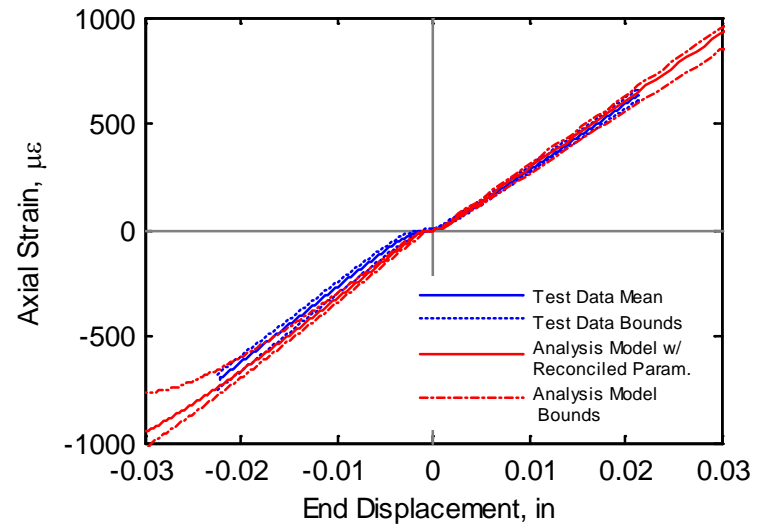

(b) Axial strain

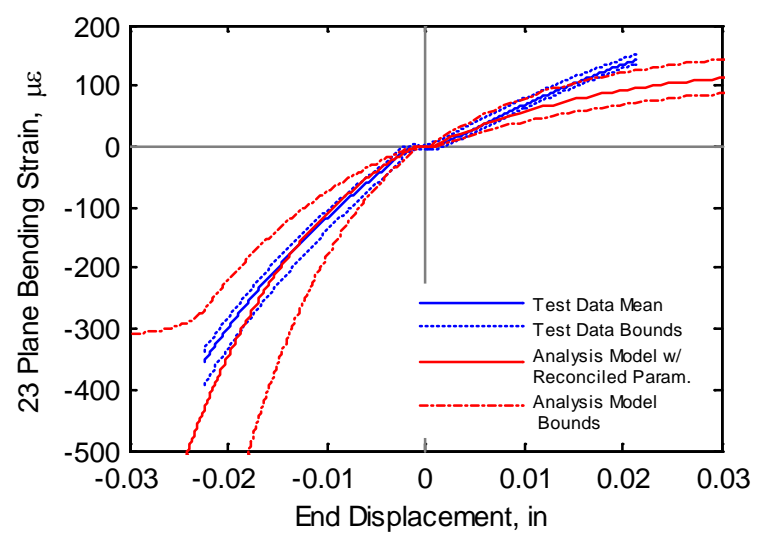

(d) 23-Plane bending strain

Figure 14. Tapered-longeron model response.

\section{Concluding Remarks}

An approach for the calibration of structural models to predict the on-orbit thermal shadowing performance of the ISS solar array is presented. The approach uses a building-block methodology that relies on calibration and validation data to improve the predictive capability of the model. In this work, the term model refers not only to a finite element model, but also to a parameter uncertainty model. The strategy discussed uses data from calibration and validation tests along with various calibration metrics to reconcile the model with test. Three calibration metrics are defined and used throughout the paper: 1) a probabilistic based metric to assess the validity of the FE model and the parameter uncertainty model, 2) a set of scalar metrics to determined parameters values to reconcile test with analysis (from a deterministic viewpoint), and 3) a scalar metric used to optimize the parameter distribution function. In this paper, the calibration strategy is demonstrated using the longerons of the ISS solar array mast. Straight-longeron models are calibrated against stiffness and buckling test data. Subsequently, the straight-longeron results are used to develop models for the tapered longerons and this is assessed against stiffness test data as a validation of the modeling assumptions.

In performing the calibration of the straight longerons, determining the appropriate model parameters and their distributions proved to be the most difficult task. The initial parameter set and distributions were developed using initial sensitivity studies and engineering judgment. Using the initial parameter set resulted in a model that had less 
than a $0.2 \%$ chance of reconciling the analysis responses with the test responses. Significant work was performed to determine a revised set of parameters and distribution to satisfy the calibration metric. These parameters were optimized to produce a parameter set and distributions that reconciled the analysis to test. The objective of this optimization was to minimize the difference between the analysis mean response and the test mean response. The calibrated parameters and distributions provided a model with bounds that closely match the load, the axial strain, and bending strains in two orthogonal planes.

For validation, the results for the straight longeron were used to model the tapered longeron. The performance of this model was assessed relative to stiffness test data. Although the mean response for load, axial, and bending strain, in compression, agreed well, the tension responses and analysis bounds for the tapered longeron were outside the test bounds.

\section{References}

${ }^{1}$ Bowden, M. L. and Woolery, B. K., “Space Station Solar Array Deployment Mast,” Paper No. IAF-92-0697, 43rd Congress of the International Astronautical Federation, August 28-September 5, 1992, Washington, DC.

${ }^{2}$ Bowden, M. L. and Benton, M., "Design of Deployable-Truss Masts for Space Station,” AIAA Paper No. 93-0975, AIAA/AHS/ASEE Aerospace Design Conference, February 16-19, 1993, Irvine, CA.

${ }^{3}$ Takeda, R., Robinson, S., Klein, S., Eacret, D., and Bowden, M., Mast-Canister Failure and Strength Assessment Final Report, Report No. AEC94518R921 Rev. A, AEC-Able Engineering Company, Goleta, CA, May 17, 1994.

${ }^{4}$ Shaker, J. F., "Static Stability of a Three-Dimensional Space Truss," Proceedings of the 13th Space Photovoltaic Research and Technology Conference (SPRAT-13), NASA Lewis Research Center, June 14-16, 1994, NASA CP-3728, pp. 299-312, September 1994.

${ }^{5}$ Tang, C. C., Elliott, A. J., Bowden, M. L., and Robinson, S. "Static Test and Nonlinear Analysis of the Mast for International Space Station Alpha Solar Array Wing,” 1995 MSC World Users’ Conference, Paper No. 28, Universal City, CA, May 812, 1995.

${ }^{6}$ Robinson, S. and Trautt, T., Solar Array Mast Buckling Analysis Report for the ISS Solar Array Mast, ATK Space Systems, Report No. 1163D3883, Rev. C, May 11, 2011. Pending NASA Contractor Report, 2012.

${ }^{7}$ The American Society of Mechanical Engineers, Guide for Verification and Validation in Computational Solid Mechanics, ASME V\&V 10-2006, ASME, New York, 2006

${ }^{8}$ Pham, H. Q. and Slucter, J., ISS Solar Array Wing Mast Shadowing Thermal Vacuum Test Report, Jet Propulsion Laboratory, Report No. JPL-D-49526, January 15, 2009.

${ }^{9}$ Pham, H. Q., ISS Solar Array Wing Mast Shadowing 32 Bay Thermal Model Report, Jet Propulsion Laboratory, Report No. JPL-D-61740, June 22, 2009.

${ }^{10}$ Knight, N. F, Jr, Elliott, K. B., Templeton, J. D., Song, K., and Rayburn, J. T., "FAST Mast Structural Response to Axial Loading: Modeling and Verification,”, AIAA Paper to be presented at the 53rd AIAA/ASME/ASCE/AHS/ASC Structures, Structural Dynamics, and Materials Conference, Honolulu, HI, April 23-26, 2012.

${ }^{11}$ Moore, T. C., Sr., "NESC ISS Solar Array Mast Structural Assessment: Strain Gauge and Thermocouple Installation Procedure,” Dwg No. 235305-1264191, NASA Langley Research Center, Hampton, VA, 2008.

${ }^{12}$ Lake, M. S. and Hachkowski, M, R., Design of Mechanisms for Deployable, Optical Instruments: Guidelines for Reducing Hysteresis, NASA TM-210089, March 2000.

${ }^{13}$ Halton, J. H., "On the Efficiency of Certain Quasi-Random Sequences of Points in Evaluating Multi-Dimensional Integrals,” Numerische Mathematik, Vol. 2, pp.84-90, 1960.

${ }^{14}$ Mullur, A. and Messac, A., "Extended Radial Basis Functions: More Flexible and Effective Metamodeling," AIAA Journal, Vol., 43, No. 6, June 2005. 